\title{
Design of the POINT study: Pharmacotherapy Optimisation through Integration of a Non-dispensing pharmacist in a primary care Team (POINT)
}

Ankie C.M. Hazen ${ }^{1 \dagger}$, Vivianne M. Sloeserwij ${ }^{1{ }^{*}}$, Dorien L.M. Zwart ${ }^{1}$, Antoinette A. de Bont ${ }^{2}$, Marcel L. Bouvy ${ }^{3}$, Johan J. de Gier ${ }^{4}$, Niek J. de Wit ${ }^{1}$ and Anne J. Leendertse ${ }^{1}$

\begin{abstract}
Background: In the Netherlands, $5.6 \%$ of acute hospital admissions are medication-related. Almost half of these admissions are potentially preventable. Reviewing medication in patients at risk in primary care might prevent these hospital admissions. At present, implementation of medication reviews in primary care is suboptimal: pharmacists lack access to patient information, pharmacists are short of clinical knowledge and skills, and working processes of pharmacists (focus on dispensing) and general practitioners (focus on clinical practice) match poorly. Integration of the pharmacist in the primary health care team might improve pharmaceutical care outcomes.

The aim of this study is to evaluate the effect of integration of a non-dispensing pharmacist in general practice on the safety of pharmacotherapy in the Netherlands.

Methods: The POINT study is a non-randomised controlled intervention study with pre-post comparison in an integrated primary care setting. We compare three different models of pharmaceutical care provision in primary care: 1) a non-dispensing pharmacist as an integral member of a primary care team, 2) a pharmacist in a community pharmacy with a predefined training in performing medication reviews and 3) a pharmacist in a community pharmacy (care as usual). In all models, GPs remain accountable for individual medication prescription. In the first model, ten non-dispensing clinical pharmacists are posted in ten primary care practices (including $5-10000$ patients each) for a period of 15 months. These non-dispensing pharmacists perform patient consultations, including medication reviews, and share responsibility for the pharmaceutical care provided in the practice. The two other groups consist of ten primary care practices with collaborating pharmacists. The main outcome measurement is the number of medication-related hospital admissions during follow-up. Secondary outcome measurements are potential medication errors, drug burden index and costs. Parallel to this study, a qualitative study is conducted to evaluate the feasibility of introducing a NDP in general practice.
\end{abstract}

Discussion: As the POINT study is a large-scale intervention study, it should provide evidence as to whether integration of a non-dispensing clinical pharmacist in primary care will result in safer pharmacotherapy. The qualitative study also generates knowledge on the optimal implementation of this model in primary care. Results are expected in 2016.

Trial registration number: NTR4389, The Netherlands National Trial Register, 07-01-2014.

Keywords: Pharmacotherapy, Polypharmacy, Non-dispensing clinical pharmacist, General practice, Primary care, Hospitalisation

\footnotetext{
* Correspondence: v.sloeserwij@umcutrecht.nl

${ }^{\dagger}$ Equal contributors

'Department of General Practice, Julius Centre for Health Sciences and

Primary Care, University Medical Centre Utrecht, Utrecht, The Netherlands

Full list of author information is available at the end of the article
}

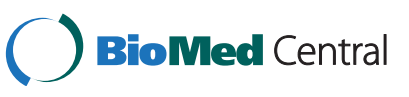

(c) 2015 Hazen et al. This is an Open Access article distributed under the terms of the Creative Commons Attribution License (http://creativecommons.org/licenses/by/4.0), which permits unrestricted use, distribution, and reproduction in any medium, provided the original work is properly credited. The Creative Commons Public Domain Dedication waiver (http://creativecommons.org/publicdomain/zero/1.0/) applies to the data made available in this article, unless otherwise stated. 


\section{Background}

Adverse drug events account for 5,6 \% of acute hospital admissions in the Netherlands. Almost half of these admissions are potentially preventable [1]. Older age, polypharmacy, multimorbidity, impaired cognition and impaired renal function have been identified as risk factors for these preventable medication-related hospital admissions (HARMs) [1]. Given the ageing of the population, the population at risk will grow in near future. Hence, new strategies are needed to improve the effectiveness and safety of pharmacotherapy in clinical practice and to prevent these hospital admissions.

As most of the pharmacotherapy is initiated in general practice, its quality may be primarily improved by structural reviewing patients' medication in primary care. So far, the results of studies on the effectiveness of medication reviews have been inconclusive: several studies reported a positive effect on the number of drug therapy problems [2-7], but no effect on morbidity, mortality or quality of life was found.

Several difficulties hamper the implementation of medication reviews in primary care [8-10] and may have contributed to the inconclusiveness of these results. First of all, as community pharmacists get no or an insufficient fee for performing medication reviews, a financial incentive is lacking. However, this does not seem to be the only problem. Another important difficulty in the implementation is the lack of information: community pharmacists do not have access to routine patient records. Consequently, performing proper medication reviews is often impeded, as not all available information can be taken into account. Third, pharmacists lack clinical pharmacology knowledge and clinical reasoning skills, for pharmaceutical training and practice are historically drug product oriented instead of patient oriented. Community pharmacists' tasks mainly concern the organisation and monitoring of logistic processes (e.g. dispensing the right medication in the right dose to the right patient); community pharmacists perform little to no direct pharmaceutical patient care. As a result, pharmacists have sparse experience in clinical pharmacotherapy. Fourth, in the present system pharmacists and general practitioners (GPs) have different responsibilities, backgrounds and working processes, resulting in inadequate collaboration [11]. Fifth, the present way of practicing of both GPs and pharmacists is mainly reactive, while the pharmaceutical care process requires a proactive approach. Finally, there is a misfit between time-consuming nature of performing medication reviews and the current workload of both GPs and pharmacists.

Implementation of a non-dispensing pharmacist (NDP) in primary care teams might address these implementation problems and improve outcomes of pharmaceutical care. The NDP - as a healthcare team member - would have access to patient records and the required clinical information. The lack of clinical knowledge and skills of the pharmacist could be overcome by a training in clinical pharmacy. Collaboration with the GP is expected to improve, because the NDP is positioned into the clinical practice and is a full member of the primary care team, with the GP as head of the team. Furthermore, as the NDP's scope alters from drug product oriented to patient oriented, the professional perspective will collide better with that of the GP $[12,13]$. Finally, this change in scope relieves the NDP of his responsibility for the dispensing process, and enables the NDP to work fulltime on the improvement of pharmacotherapy.

This model of integrated pharmaceutical care has already been studied in Canada [14, 15], Australia [16] and the United States of America [17]. It was found that the model has the potential to address many of the barriers to effective pharmaceutical care in the ways described above, thereby optimising medication use and hence leading to better healthcare outcomes $[14,16]$. In Canada, physicians recognised many interprofessional benefits by working with a pharmacist directly integrated into their practice. Also, benefits of improved education were described [14]. The Australian study reported a significant reduction in medication-related problems after intervention by the pharmacists, and a significant improvement of adherence to the medication regimen [16]. In the USA, both GPs and patients perceived qualitative benefits from the pharmacotherapy consultations [17].

However, the ultimate benefit of this model for patients, namely the prevention of HARMs, has not been demonstrated yet. Therefore, we designed the Pharmacotherapy Optimisation through Integration of a Nondispensing pharmacist in a primary care Team (POINT) study, in which we assess, amongst others, the effect of a non-dispensing pharmacist on medication-related hospital admissions.

\section{Methods \\ Design}

The POINT study is a non-randomised, controlled intervention study with pre-post comparison (see Table 1 for a time schedule of the POINT study). Three different

Table 1 Time schedule of the POINT-study

\begin{tabular}{|c|c|}
\hline Period & Dates \\
\hline Pre intervention period (1 year) & $\begin{array}{l}1^{\text {st }} \text { of January } 2013-31^{\text {st }} \\
\text { of December } 2013\end{array}$ \\
\hline $\begin{array}{l}\text { Start-up period, prior to intervention } \\
\text { period ( } 3 \text { months) }\end{array}$ & $\begin{array}{l}1^{\text {st }} \text { of March } 2014-31^{\text {st }} \text { of } \\
\text { May } 2014\end{array}$ \\
\hline Intervention period (1 year) & $\begin{array}{l}1^{\text {st }} \text { of June } 2014-31^{\text {st }} \text { of } \\
\text { May } 2015\end{array}$ \\
\hline
\end{tabular}


models of pharmaceutical care provision in primary care will be compared:

- Group A (intervention group): a GP practice with a non-dispensing pharmacist based in the practice as an integral member of the primary healthcare team;

- Group B (control group 1): 'upgraded' care as usual: a GP practice collaborating with a dispensing pharmacist based in a community pharmacy in the traditional way, with the pharmacist having had a predefined, certified additional training in reviewing medication,

- Group C (control group 2): care as usual: a GP practice collaborating with a dispensing pharmacist based in a community pharmacy in the traditional way.

A flowchart of the study design is shown in Fig. 1. Concurrently, a qualitative implementation study is performed.

The protocol was peer-reviewed by the funding organisation.

\section{Setting}

The project is implemented within primary care practices from the Julius General Practitioners Network (University Medical Centre Utrecht) and the Academic Network of General Practitioners (VU University Medical
Centre Amsterdam). These networks consist of more than 200 collaborating general practices.

\section{Group A: selecting GPs, non-dispensing pharmacists and matching both}

General practices from the above mentioned networks are all pro-actively invited to participate in the POINT study. Ten general practices are selected, based on the following criteria: willingness of the GPs to participate in the project; willingness of the GPs to cooperate in the development and evaluation of the role of the NDP; minimum of 5000 registered patients; availability of an office for a NDP, with access to the GP information system; minimum of one practice nurse working on disease management programs for chronic conditions such as chronic obstructive pulmonary disease, diabetes, cardiovascular disease or mental health; healthcare centre accredited by the Dutch College of General Practitioners (NHG) [18]. The research collaboration is formalised in a collaboration agreement.

Ten non-dispensing pharmacists are employed, using a structured application procedure. All participating pharmacists have a master degree in pharmacy (PharmD) and preferably have working experience in providing pharmaceutical care to individual patients. Furthermore,

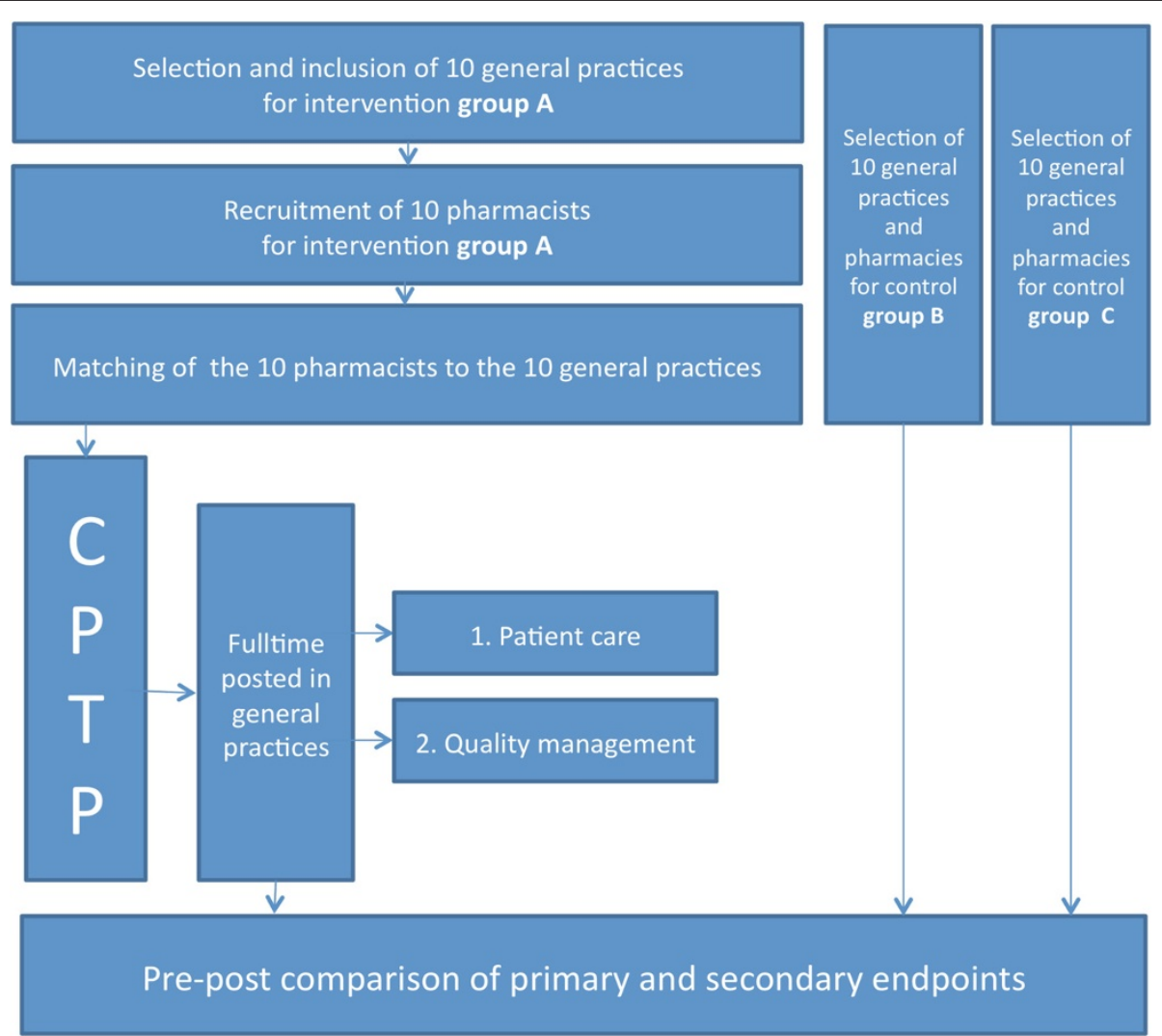

Fig. 1 Flowchart of the study design. Abbreviations used: CPTP Clinical Pharmacy Training Program (newly developed for the intervention) 
in the selection procedure communication and collaboration skills, as well as pharmacotherapy knowledge, empathy, self-reflection skills and innovative attitude are emphasized.

Subsequently, each NDP is posted in one of the ten selected primary care centres in Utrecht or Amsterdam regions. The NDPs work full time and exclusively in the general practices, for a period of 15 months. The introduction of such a new role in a healthcare practice is complicated and faces a variety of challenges [14]. For example, pharmacists need to be trained to fulfil their new tasks, both pharmacists and GPs have to collaborate closely and GPs have to explore the complementary role of the NDP. Therefore, the first three months are used as a start-up period before actually starting the intervention period.

\section{Group B and C: selecting GPs and collaborating pharmacists}

For both group $\mathrm{B}$ and $\mathrm{C}$, ten general practices and collaborating pharmacies are selected from the abovementioned networks as well. Criteria for participation are comparable to those concerning the size of the practices, described for group A. In addition, characteristics of patients of practices in groups $B$ and $C$ were matched as far as possible with group A, considering age distribution and socioeconomic status. Subsequently, practices and collaborating pharmacies are assigned to group B or
C, depending upon whether the collaborating pharmacists have completed a certified training program on performing medication reviews in the Netherlands $[19,20]$, or not, respectively. See Fig. 2.

\section{Intervention}

To improve the safety of pharmacotherapy within the general practice, the intervention in group A by the NDPs aims at two levels: individual patient consultation and quality management on an organisational level. Herewith, the NDPs are responsible for the medication management and pharmaceutical care provided in the general practice. The NDPs perform complementary work and do not take over tasks of the GP nor the community pharmacist.

\section{Individual patient consultation}

The patient care process consists of an assessment of the patient's drug-related needs, a care plan to meet the specific needs of the patient, and a follow-up evaluation to determine the impact of the decisions made and actions taken. In practice, the NDP provides pharmaceutical patient care for patients who are considered to be at risk of adverse drug events, such as HARMs. These patients, mostly of older age, with multimorbidity and polypharmacy (chronic use of five or more medicines) [1], are either pro-actively invited by the NDP or referred by the GP to discuss and review their medication. Also, patients can make an appointment for a medication

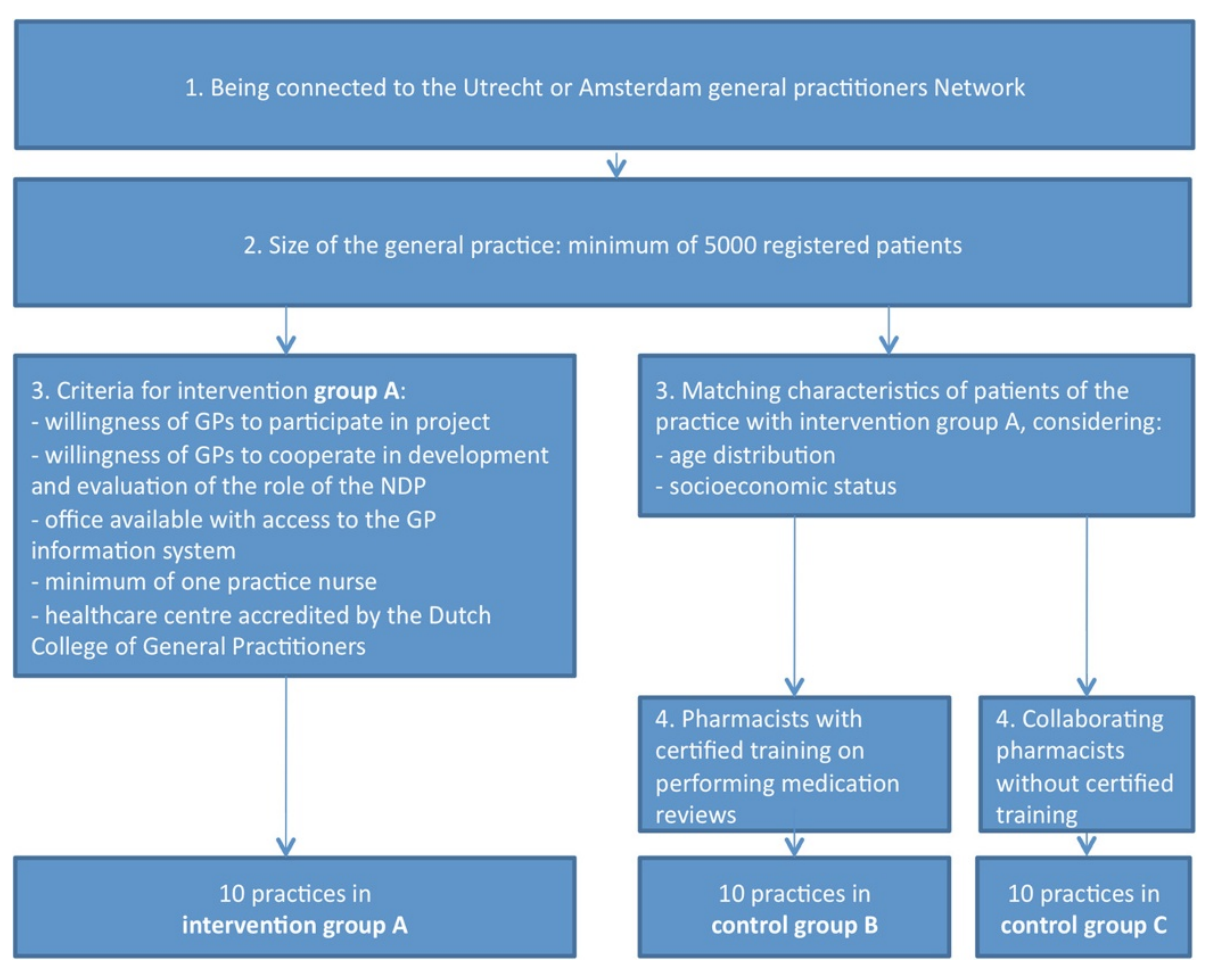

Fig. 2 Overview of the selection criteria for general practices for group A, B and C 
assessment at their own request. During the first consultation, which is preferably a home visit, the NDP will work on a therapeutic relationship and interviews the patient to gather information on the patient's experiences with and believes about medication, in order to assess his or her drug-related needs. Questions concern the goal of therapy for the patient, the current and past medication history, adherence to the medication regimen and patient reported medication issues. Afterwards, the NDP integrates the patient reported experiences and believes with the medical status to determine whether there are potential drug therapy problems. If necessary, the NDP provides recommendations for optimisation of pharmacotherapy to the GP: suggestions to stop, start or switch medication, to adjust dosages, or for actions to improve adherence. These recommendations result in a documented individual pharmaceutical care plan, as part of the patient's medical record. The implementation of recommendations is monitored by the NDP. Follow-up contacts can be conducted as a home visit, a practice visit or by telephone.

Furthermore, the NDP covers other aspects of pharmaceutical patient care, such as individual consultations for specific drug therapy problems or questions, and medication reconciliation in patients discharged from hospital.

All patient level interventions involve ongoing onlocation collaboration with the healthcare team - being GP, practice nurses, assistants and the community pharmacists. The NDP is available at the GP practice and has daily formal and informal meetings with the GP in order to establish individual pharmaceutical care plans and to report on plans in progress. All members of the healthcare team can easily approach the NDP with questions about medication and patients' pharmacotherapy.

\section{Quality management}

The NDP aims to improve medication safety on an organisational level, through optimisation of processes within the practice around repeat prescribing, clinical care paths, administrative efficiencies and identification of common medication errors. The NDP is looking for possible optimisation options in medication regimens, such as monitoring renal function and electrolytes with indicated pharmacotherapy, tapering the chronic use of proton pump inhibitors, and optimising antibiotic prescribing. Hereby, the NDP organises targeted programs to improve the quality of pharmaceutical care in the practice. Also, the NDP provides education of patients and professionals involved.

\section{Training program group $A$}

To train the NDPs for their new role, a specialised Clinical Pharmacy Training Program (CPTP) is developed, based on workplace learning and the Canadian Medical Education Directions for Specialists (CanMEDS) Roles
[21]. The CPTP started with a six-day training workshop, an internship in a nursing home and assignments in practice. Plenary education days are gradually decreased and days in the general practice gradually increased, ending with full time practice work with weekly education days at the university. Key elements of the training are consultation and communication skills, clinical reasoning, clinical pharmacotherapy and being reflective in practice. NDPs are trained to use a patient centred approach in providing care, instead of a drug product centred approach. Barriers to implementation are discussed and ongoing support is provided through structural intervision sessions and a mentorship and buddy program [22].

\section{Outcomes and measurements}

\section{Primary outcome: medication-related hospital admissions (HARMs)}

The primary outcome is the number of medicationrelated hospital admissions (HARMs) in the high-risk population. HARMs are defined as hospitalisations related to adverse drug events. To identify these medicationrelated hospital admissions, two pharmacists with clinical experience will independently assess each hospitalisation that occurred in the study population during follow-up, using discharge information combined with the medical and medication history. They will assess the causal relationship between the suspected medicine and the reason for hospitalisation, according to an adjusted version of the algorithm by Kramer et al. [23]. In this version, three questions need to be answered (in contrast to six questions in the original algorithm): whether the reason for admission is known to be an adverse event of the suspected medicine, whether alternative causes can explain the relationship between the suspected medicine and the adverse event, and whether a plausible time relationship exists between the adverse event and the start of medication administration (or the occurrence of the medication error). On the basis of the answers, causality is classified as "possible", "probable", or "unlikely". Cases with an assessment of unlikely will be excluded.

\section{Secondary outcomes}

Potential medication errors The percentage of patients with potential medication errors will be measured [24]. These potential medication errors mainly concern prescription errors, such as under- and overprescribing and dosage errors. Other potential medication errors might be due to medication that is not or insufficiently effective, or to inadequate monitoring of the effects of the therapy. Also administration errors, such as non-adherence problems, will be measured as potential medication errors. A complete list of included potential medication errors can be found in Table 2 . 
Table 2 Overview of outcomes, measurements and data sources

\begin{tabular}{lll}
\hline Outcomes & Measurement & Data sources \\
\hline Primary outcome & Number of HARMs & DL, MH, MED \\
Frequency of HARMs & \% patients with: & MED/MR \\
Pecondary outcomes & - medication not indicated & MED/MR \\
& - underprescribing & MED/MR \\
& - dosing error (too low or too high) & MED/MR \\
& - therapeutic duplication medication & MED/MR \\
& - medication contra-indicated & MED/MR \\
& - drug-drug interactions & MED/MR \\
& - medication not effective & MED/MR \\
- inadequately monitored therapy & MED/MR \\
Drug burden index & - administration errors (e.g. non-adherence) & Mrug burden of medications with sedative and/or anticholinergic effects \\
\hline
\end{tabular}

HARM hospital admission related to medication, DL discharge letter, MH medical history (with ICPC codes for diagnoses), MED medication records (including ATC code, dose and strength), MR medical records (including laboratory markers and measurements such as blood pressure, pulse and body mass index)

Drug burden index The drug burden index will be calculated for every patient. This drug burden index measures exposure to anticholinergic and sedative medication, and is associated with poorer physical and cognitive performance in older people [25]. Hence, the drug burden index can be seen as a proxy of drug therapy risk and medication safety.

Costs A cost analysis will be performed, based upon reimbursement data from databases of a Dutch major health insurance company. Direct medical costs, such as for medication, hospital care, specialist care, diagnostic tests and other healthcare-related costs will be included.

\section{Data collection}

Data of all patients in groups A, B and C are accessible through the routine health care databases of the Julius General Practitioners Network (Utrecht) and the Academic Network of General Practitioners (Amsterdam). After the intervention period (see Table 1), key data will be extracted anonymously from the electronic medical records in the general practices of both the pre- and post-intervention period, through standard procedures and existing algorithms. These data (see Table 2) are combined with reimbursement data from the major healthcare insurance company in the Utrecht and Amsterdam region, obtaining $40-55 \%$ of the reimbursement data of the region. No data will be obtained directly from patients.

\section{Confounding factors}

To be able to control for possible confounding, characteristics of the involved general practices and pharmacies in each group will be collected, using a questionnaire. Additional information will be gathered about pharmaceutical care provision, the medication review protocol used, the setting of the pharmacy and the general practice, the collaboration between the pharmacy and the general practice and agreements on pharmaceutical care provision.

\section{Analyses and statistical method}

All primary and secondary outcomes will be compared in pre-post analyses and between groups comparisons will be conducted. Descriptive statistics will be calculated for the baseline characteristics according to data of the overall population in group A, B and C, as well as for the high risk patients. The effect on the primary outcome will be tested with logistic multilevel analysis. The potential medication errors, drug burden index and costs will be tested with mixed effect models. Baseline characteristics can be integrated into the mixed effect models to control for confounding.

\section{Sample size calculation}

With an expected prevalence of 4,5\% HARMs in 12 months within the high-risk population [26], we expect an effect of $50 \%$ reduction of HARMs [1]. To show a statistically significant difference between the intervention group A and control group C, we include ten practices, with a total of 45.000 patients, in each group. As $6,4 \%$ of patients in an average GP practice are part of the high risk elderly population [26], this means that in each arm at least 2850 high risk patients are included. This is based on an alpha of 0,05 and a power (1-beta) of 0,8. 


\section{Qualitative study}

In order to assess the feasibility of introducing a NDP in general practice, parallel to the POINT study qualitative data hereon is systematically collected. Semi-structured interviews with participating GPs and NDPs are conducted, and their views are described. Patients who are seen by a NDP are asked about their perceptions and experiences, using anonymised questionnaires. Hereby, conditions that hinder or facilitate the introduction of a NDP in general practice in the Netherlands may be identified.

\section{Privacy and informed consent/Ethical approval}

Based on the Dutch law for patient data protection, this study was exempt of formal medical-ethical approval by the Medical Ethical Committee University Medical Centre Utrecht. (METC protocol number 13-432C).

\section{Discussion}

The POINT study aims to improve safety of pharmacotherapy in primary care, by introducing a non-dispensing pharmacist as a member of the primary care team in the Netherlands. This intervention aims to improve pharmaceutical care at both patient level and organisational level. Therefore, it may be more effective than a singular intervention, such as current medication reviews. A comparison will be made with two existing models of pharmaceutical care provision in primary care. This comparison will demonstrate whether the introduction of the NDP is more effective in improving the quality and safety of pharmacotherapy than existing care models.

Several methodological challenges were faced during the design of the POINT study.

\section{Choice for the design}

Despite the fact that a randomised controlled trial is the preferred design to evaluate the effect of an intervention, we thoughtfully chose to use a non-randomised model. In our opinion, willingness of all participating parties to improve pharmaceutical patient care is a key condition for the implementation of this intervention to succeed. This has been recognised before, during the implementation of a pharmacist in primary care in Canada [14]. Therefore, general practices participating in the intervention group of this study are selected instead of randomly allocated to one of three research arms.

This selection, of course, has disadvantages. Once proven effective, the broad implementation of this new function might be challenging because of the high standards we set for participating practices in this study. In addition, selection of motivated general practices might mask the effect of the intervention. As these practices are motivated to improve pharmaceutical care, standard pharmaceutical care might be better than average beforehand, leaving little room for improvement. By including pre-post analyses, we attempt to obviate this problem.

\section{Composition of the intervention}

The introduction of the NDP is considered a complex intervention. This is for intervening at different care levels, as well as for integrating a new professional into the primary work processes, which requires redistribution of tasks and responsibilities around pharmacotherapeutic care. Although the tasks of the NDP are predefined, the actual implementation in the individual GP practices cannot be protocolled: in order to increase the likelihood of a successful implementation of the intervention, the intervention has to be aligned to the needs of each participating centre. Consequently, the actual implementation of the intervention itself may be heterogeneous. This can blur quantitative measurements. Therefore, parallel to this study, we conduct a qualitative study as described earlier. With this study, we will list facilitators and barriers to the implementation process, in order to assess the feasibility of introducing a NDP in a complex healthcare setting in daily practice.

\section{Development of the clinical pharmacy training program}

The clinical pharmacy training program (CPTP) has been newly developed for the POINT study and has neither been validated nor accredited. As the CPTP is developed by experts in the field of education, based on the theoretical frameworks of Vermunt, Kolb and Merrienboer [27-29] and as it is embedded in the department of vocational training for general practice, it is expected to be an adequate postgraduate training for the NDPs. Within the context of the POINT intervention study, the program is evaluated and attuned on a structural basis.

\section{Choice of the primary outcome measurement}

In the context of 'primum non nocere' [30] the prime aim of this study is to improve the safety of pharmacotherapy. Therefore, we chose reduction of medicationrelated hospital admissions (HARMs), being a severe adverse drug event, as primary outcome. This choice is, however, challenging in several aspects.

First, the incidence of HARMs in primary care is low. Although $5.6 \%$ of acute hospital admissions are related to medication [1], this accounts for only about 3.4 medication-related hospital admissions per GP on a yearly basis - which means around 12-16 HARMs per participating practice in this study. In addition, we do have a limited follow-up period of only one year. However, our sample size calculation is based upon the occurence of HARMs in a large group, so we expect this problem to be adequately addressed. Last, measuring HARMs is 
challenging for quite detailed data have to be obtained in order to determine HARMs. Causality assessments in the POINT study will be based upon information of discharge letters, which is limited information. However, using this amount of information to determine HARMs has been done before [31]. Also, we do have experience from previous studies $[1,26]$ and will use a validated method to identify the primary outcome parameter.

\section{Availability of data for secondary outcome measurements}

To correctly measure and analyse the secondary outcomes, the required data need to be properly documented in the GPs' information systems. Due to the heterogeneous study setting we are dependent on the diverse working methods of the participating healthcare providers. As this possible loss of information will show equally in each research arm, we expect this will not influence our study results.

The cost evaluation performed in this study will yield an insight in the direct medical costs of each model of pharmaceutical care provision in primary care. For this evaluation, a subgroup of patients will be analysed, as data of the insurance company will not be available for all patients. A full economic evaluation including a societal costs and economic modelling is outside the scope of this research project.

\section{Conclusion}

This study will provide information as to whether the integration of a non-dispensing pharmacist in primary care will improve medication safety compared to current care models.

\section{Abbreviations \\ HARM: Hospital Admission Related to Medication; GP: General Practitioner; NDP: Non-Dispensing Pharmacist; POINT: Pharmacotherapy Optimisation through Integration of a Non-dispensing pharmacist in a primary care Team; CPTC: Clinical Pharmacy Training Program.}

\section{Competing interests}

The authors declare that they have no competing interests.

\section{Authors' contributions}

AJL, DLMZ, AdB, MB, JJdG and NJW participated in the design of the trial and study methodology. ACMH and VMS (both PhD candidates), AJL and DLMZ participated in the manuscript preparation and $\mathrm{ACMH}$ has an ongoing role in carrying out the trial. NJW and MLB reviewed the manuscript. All authors read and approved the final manuscript.

\section{Acknowledgements}

The POINT-project is funded by The Netherlands Organisation for Health Research and Development (ZonMW). Implementation of NDPs was supported by the Dutch health insurance company Agis/Achmea.

\section{Author details}

'Department of General Practice, Julius Centre for Health Sciences and Primary Care, University Medical Centre Utrecht, Utrecht, The Netherlands. ${ }^{2}$ Institute of Health Policy and Management, Erasmus University Rotterdam, Rotterdam, The Netherlands. ${ }^{3}$ Department of Pharmaceutical Sciences, Utrecht University, Utrecht, The Netherlands. ${ }^{4}$ Department of Pharmacotherapy and Pharmaceutical Care, University of Groningen, Groningen, The Netherlands.
Received: 1 June 2015 Accepted: 15 June 2015

Published online: 02 July 2015

\section{References}

1. Leendertse AJ, Egberts ACG, Stoker LJ, van den Bemt PMLA. Frequency of and risk factors for preventable medication-related hospital admissions in the Netherlands. Arch Intern Med. 2008;168:1890-6.

2. Denneboom W, Dautzenberg MG, Grol R, de Smet PA. Treatment reviews of older people on polypharmacy in primary care: cluster controlled trial comparing two approaches. Br J Gen Pract. 2007;57:723-31.

3. Kwint HF, Faber A, Gussekloo J, Bouvy ML. Effects of medication review on drug-related problems in patients using automated drug-dispensing systems: a pragmatic randomized controlled study. Drugs Aging. 2011;28:305-14.

4. Stuijt CC, Franssen EJ, Egberts AC, Hudson SA. Appropriateness of prescribing among elderly patients in a Dutch residential home: observational study of outcomes after a pharmacist-led medication review. Drugs Aging. 2008;25:947-54

5. Vinks TH, Egberts TC, de Lange TM, de Koning FH. Pharmacist-based medication review reduces potential drug-related problems in the elderly: the SMOG controlled trial. Drugs Aging. 2009;26:123-33.

6. Kempen TG, van de Steeg-van Gompel CH, Hoogland P, Liu Y, Bouvy ML. Large scale implementation of clinical medication reviews in Dutch community pharmacies: drug-related problems and interventions. Int J Clin Pharm. 2014;36:630-5.

7. Chau SH, Jansen APD, van de Ven PM, Hoogland P, Elders PJM, Hugtenburg JG. Medicatiebeoordelingen in de openbare apotheek: prevalentie van geneesmiddelgerelateerde problemen bij ouderen met polyfarmacie en inzicht in patiënt-, behaldelings- en ziektegerelateerde factoren. PW Wetenschappelijk Platform. 2014;8:a1428.

8. Leendertse AJ. Dissertation: Hospital admissions related to medication: prevalence, provocation and prevention. Chapter 3.2 The effect of a pharmaceutical care process intervention on medication-related hospital admissions in the elderly in an integrated primary care setting: results of the PHARM study, Appendix "The discrepancy between intended and actual number of included patients in the PHARM-study". p. 159-62.

9. Edmunds J, Calnan MW. The reprofessionalisation of community pharmacy? An exploration of attitudes to extended roles for community pharmacists amongst pharmacists and General Practioners in the United Kingdom. Soc Sci Med. 2001;53:943-55.

10. Farris KB, Côté I, Feeny D, Johnson JA, Tsuyuki RT, Brilliant S, Dieleman S. Enhancing primary care for complex patients. Demonstration project using multidisciplinary teams. Can Fam Physician. 2004;50:998-1003.

11. Kwint HF, Bermingham L, Faber A, Gussekloo J, Bouvy ML. The relationship between the extent of collaboration of general practitioners and pharmacists and the implementation of recommendations arising from medication review: a systematic review. Drugs Aging. 2013;30:91-102.

12. McDonough RP, Doucette WR. Dynamics of pharmaceutical care: developing collaborative working relationships between pharmacists and physicians. J Am Pharm Assoc. 2001;41:682-92.

13. D'Amour D, Ferrada-Videla M, San Martin Rodriguez L, Beaulieu MD. The conceptual basis for interprofessional collaboration: core concepts and theoretical frameworks. J Interprof Care. 2005;19 Suppl 1:116-31.

14. Dolovich L, Pottie K, Kaczorowski J, Farrell B, Austin Z, Rodriguez C, Gaebel $K$, Sellors $C$. Integrating family medicine and pharmacy to advance primary care therapeutics. Clin Pharmacol Ther. 2008;83:913-7.

15. Hogg W, Lemelin J, Dahrouge S, Liddy C, Armstrong CD, Legault F, Dalziel B, Zhang W. Randomized controlled trial of anticipatory and preventive multidisciplinary team care. Can Fam Physician. 2009;55:e76-85.

16. Tan ECK, Stewart K, Elliott RA, George J. Pharmacist consultations in general practice clinics: The Pharmacists in Practice Study (PIPS). Res Social Adm Pharm. 2013:1-11.

17. Jameson JP, VanNoord GR. Pharmacotherapy consultation on polypharmacy patients in ambulatory care. Ann Pharmacother. 2001;35:835-40.

18. NHG: Nederlands Huisartsen Genootschap. https://www.nhg.org/ Accessed 19 June 2015.

19. Periodieke Individuele Analyse Farmacotherapie (PIAF). http://www. paofarmacie.nl/uploads/files/folder_PIAF_def.pdf Accessed 19 June 2015.

20. Service Apotheek Farmacotherapie Expert opleiding. http:// www.serviceapotheeknascholing.net/ Accessed 19 June 2015. 
21. CanMEDS: better standards, better physicians, better care. http:// www.royalcollege.ca/portal/page/portal/rc/resources/aboutcanmeds. Accessed 19 June 2014.

22. Balint M. The doctor, his patient and the illness. 1st ed. London: Pitman Medical Publishing; 1964

23. Kramer MS, Leventhal JM, Hutchinson TA, Feinstein AR. An algorithm for the operational assessment of adverse drug reactions. I. Background, description, and instructions for use. JAMA. 1979:242:623-32.

24. Schumock GT, Thornton JP. Focusing on the preventability of adverse drug reactions. Hosp Pharm. 1992;27:538

25. Hilmer SN, Mager DE, Simonsick EM, Cao Y, Ling SM, Windham G, Harris TB, Hanlon JT, Rubin SM, Shorr RI, Bauer DC, Abernethy DR. A drug burden index to define the functional burden of medications in older people. Arch Intern Med. 2007;167:781-7.

26. Leendertse AJ, de Koning FHP, Goudswaard AN, Belitser SV, Verhoef M, de Gier HJ, Ebgerts TCG, van den Bemt PMLA. Preventing hospital admissions by reviewing medication (PHARM) in primary care: an open controlled study in an elderly population. J Clin Pharm Ther 2013;38:379-87.

27. Vermunt JD, Verloop N. Congruence and friction between learning and teachingCongruence and friction between learning and teaching. Learn Instr. 1999:9:257-280

28. Kolb DA. The process of experiential learning. In: Kolb DA, editor. Experiential learning: experience as the source of learning and development. Englewood Cliffs, New Jersey: Prentice Hall Inc.; 1984. p. 20-38.

29. van Merriënboer JJG. Training complex cognitive skills: a four component instructional design model for technical training. Englewood Cliffs, New Jersey: Educational Technology; 1997.

30. Nederlandse artseneed. http://knmg.artsennet.nl/Publicaties/KNMG publicatie/62487/Nederlandse-artseneed-inclusief-Eed-van-HippocratesVerklaring-van-Geneve-2004.htm Accessed 19 June 2015.

31. van der Hooft CS, Dieleman JP, Siemes C, Aarnoudse AJ, Verhamme KM, Stricker BH, Sturkenboom MC. Adverse drug reaction-related hospitalisations: a population-based cohort study. Pharmacoepidemiol Drug Saf. 2008;17:365-71.

\section{Submit your next manuscript to BioMed Central and take full advantage of:}

- Convenient online submission

- Thorough peer review

- No space constraints or color figure charges

- Immediate publication on acceptance

- Inclusion in PubMed, CAS, Scopus and Google Scholar

- Research which is freely available for redistribution 